\title{
ARQUITETURAS DIGITAIS A PARTIR DO DIAGRAMA DE VORONOI E TRIANGULAÇÃO DE DELAUNAY
}

\section{DIGITAL ARCHITECTURES BY THE VORONOI DIAGRAM AND DELAUNAY TRIANGULATION}

\section{LIMA, FABIO FERREIRA}

Dr, Faculdade de Artes Visuais - Universidade Federal de Goiás; email: arqfabiolima@gmail.com.

\section{RESUMO}

Muitos modelos encontrados na natureza inspiram diversos pesquisadores, podendo ser apropriadas formas, estruturas, parâmetros de usos aplicáveis à engenharia e arquitetura, principalmente por meio de instruções computacionais. Nessas condições, esse artigo se atém aos benefícios oriundos das técnicas da Triangulação de Delaunay e do Diagrama de Voronoi. Os métodos adotados foram: revisão da literatura quanto às principais características, tecnologia da informação na construção sistemas estruturais. Os objetivos são: (1) compreender as principais qualidades que essas técnicas proporcionam, pelos padrões estendidos em nós e segmentos, conexões compositivas para pilares, treliças espaciais, grelhas metálicas. (2) apresentar alguns exemplos construídos, capazes de trazer demonstrações relevantes; (3) expor as qualidades expressivas advindas das técnicas. Esses modelos se configuram como estratégias computacionais a partir de geometrias estáveis e coesas, em abordagens estruturais consistentes.

PALAVRAS-CHAVE: Triangulação de Delaunay; Diagrama de Voronoi; Performance arquitetônica e estrutural.

\section{ABSTRACT}

Many models found in nature inspire several researchers, and may be appropriate forms, structures, parameters of uses applicable to engineering and architecture, mainly through computational instructions. Under these conditions, this article is related to the benefits derived from the techniques of the Delaunay Triangulation and the Voronoi Diagram. The methods adopted were: literature review on the main characteristics, information technology in the construction, structural systems. The objectives are:

(1) to understand the main qualities that these techniques provide, by the extended patterns in nodes and segments, composite connections for pillars, space trusses, metal grids. (2) to present some examples constructed, capable of bringing relevant demonstrations; (3) to expose the expressive qualities derived from the techniques. These models are configured as computational strategies from stable and cohesive geometries, in consistent structural approaches. KEYWORDS: Delaunay triangulation, Voronoi diagram, Architectural and structural performance. 


\section{INTRODUÇÃO}

Os estímulos causados pelos modelos da natureza possibilitaram ao longo dos anos inúmeras descobertas de suas propriedades. A tecnologia recôndita dos processos naturais apresenta inúmeras questões nas suas essências, de tal modo que o que se conhece pode ser sempre considerado uma aproximação aos seus fenômenos. Há determinadas soluções orgânicas que se constituem como um tipo de resposta mais adequada às adversidades sofridas, e seus princípios lógicos são um tipo de conhecimento secreto ou oculto desenvolvido pela natureza. Dentre os muitos aspectos notáveis, alguns englobam a simultaneidade de ações no desempenho funcional, a menor quantidade de material para sua estrutura e a otimização dos gastos de energia.

Com grande afinidade aos subsídios naturais, a geometria computacional utilizada para fins arquitetônicos pode ser constatada na Triangulação de Delaunay e o Diagrama de Voronoi (ou Voronoy). Utilizados na concepção de modelos digitais, constituem a consolidação de uma expressão construtiva contemporânea. Visando entender esses processos, busca-se apresentar nessa pesquisa a investigação desses recursos computacionais que vem sendo utilizados na produção arquitetônica, bem como na consolidação de novos modelos de estrutura, ampliando as táticas projetuais.

Pode-se observar que esses recursos representam uma nova expressão tectônica para a sociedade digital. Essas formas inauguram novos resultados e pertencem a atravessamentos de áreas diversas, cujas contendas servem de orientação a várias discussões desse artigo. Partindo de autores que abordam a geometria computacional (TSAI, 1993), (EMIRIS; FISIKOPOULOS, 2009) e a produção da arquitetura digital (KOLAREVIC, 2003), (KOTNIK, 2006), muitos autores têm refletido sobre esse complexo quadro que vem sendo formado. As novas estruturas e formações arquitetônicas requisitam tanto as tecnologias da informação na construção (TOLEDO, 2000) quanto as referências dos sistemas estruturais (SILVER, 2013), (ENGEL, 2013). Para que as discussões não fossem pautadas por especulações, seus autores também foram consultados (JUST / BURGEFF ARCHITEKTEN, 2016), (UN MEMORIAL, 2010), (JERDE, 2009), (VASS, 2016).

Esses autores são consensuais em admitir que o espaço computacional possibilita desenvolver inúmeras vertentes formais. Apresentam sequencias operacionais a serem desdobradas no objeto arquitetônico por meio de algoritmos. Nesse artigo, pretende-se abordar então as características decorrentes dos modelos oriundos do Diagrama de Voronoi e da Triangulação de Delaunay por processos digitais, dinamizando esses modelos e cujos resultados obtidos passam a constituir o imaginário da arquitetura digital, inserido também no contexto das mídias eletrônicas. As mudanças nos métodos projetuais da arquitetura se dão a partir dos âmbitos de concepção e do partido arquitetônico, quer esses resultados tenham fins exploratórios, de cogito especulativo, quer aqueles com fins à execução física, gerando novas vertentes nas linguagens arquitetônicas e estabelecendo conflitos com tendências historicamente constituídas.

\section{APRENDENDO COM A NATUREZA}

O Diagrama de Voronoi tem sido muito utilizado em diversas disciplinas porque se constitui de uma lógica matemática útil e bastante similar a vários padrões orgânicos encontrados na natureza. Diversos testes mostram que padrões naturais são ubíquos, como espécies de formulários vivos, presentificados nos arranjos mínimos de suas formas (EMIRIS; FISIKOPOULOS, 2009). O diagrama mimetiza uma série de casos peculiares, como a estrutura da asa da libélula, da carapaça de uma tartaruga, dos veios de uma folha, do couro malhado de uma girafa, da interação das bolhas de sabão, etc. (KOTNIK, 2006). (Ver Figura 1).

Figura 1: Exemplos de alguns padrões geométricos encontrados na natureza.
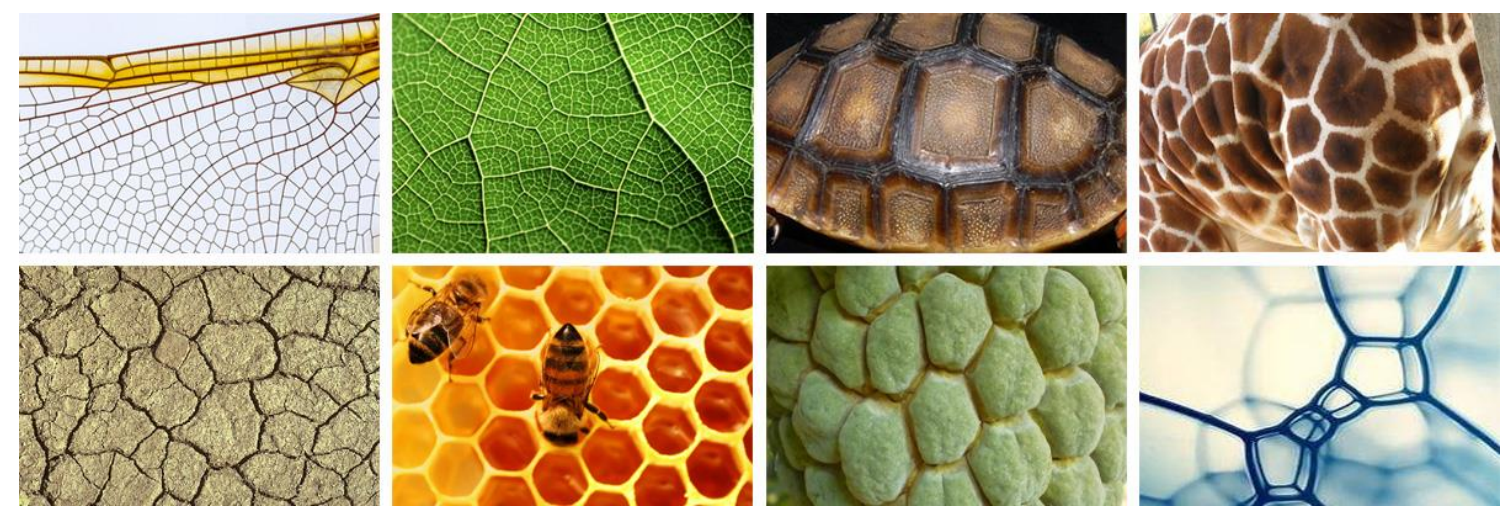

Fonte: <https://pt.dreamstime.com/> Acesso em 02 fev 2016. 
Essa decomposição espacial foi formalizada pelo matemático russo Georgy Feodosevich Voronoy em 1908. A efervescente produção dos matemáticos de Varsóvia naquela época era notável: Andrey Markov orientou Georgy Voronoy e este conduziu, posteriormente, Wacław Sierpiński (1915) e Boris Delaunay (1934). A contribuição desse grupo às mais diversas áreas apresentou-se enorme: suas inquietações matemáticas foram incorporadas às abordagens computacionais e depois transferidas aos escopos do design, das artes, da arquitetura (TSAI, 1993). A subdivisão espacial pode ocorrer tanto em duas quanto em três dimensões, perfazendo-se como elementos formais frequentes no projeto arquitetônico, planejamento urbano, geofísica, antropologia, meteorologia, dentre outras áreas. A lógica por trás da formação de tais estruturas está na associação geométrica, de modo que as forças atuantes são qualitativamente compostas, inclusive proporcionando soluções de tectônica incomum. Por meio de cálculos computacionais as soluções das formas tornam-se complexas, e ao mesmo tempo, um processo de otimização conjunta.

\section{Diagrama de Voronoi}

Por esse processo a divisão do espaço segue uma regra simples: dado um conjunto de pontos quaisquer, devem ser feitas as divisões organizadas entre eles, de modo que haja uma região para cada ponto e cujo limite é a metade da distância entre seu vizinho, formando assim polígonos convexos (ou sólidos convexos quando os pontos são distribuídos tridimensionalmente). Esses pontos são ligados por meio de segmentos de reta (formando triângulos) e depois são feitas suas mediatrizes (TSAI, 1993). Dispostas em conjunto, essas mediatrizes delimitam a forma geométrica convexa conhecida como Célula ou Diagrama de Voronoi (ver Figura 2).

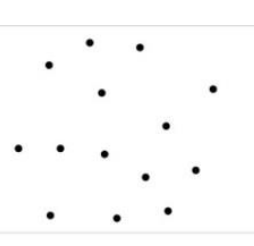

Pontos no espaço

Figura 2. Etapas para obtenção do Diagrama de Voronoi.
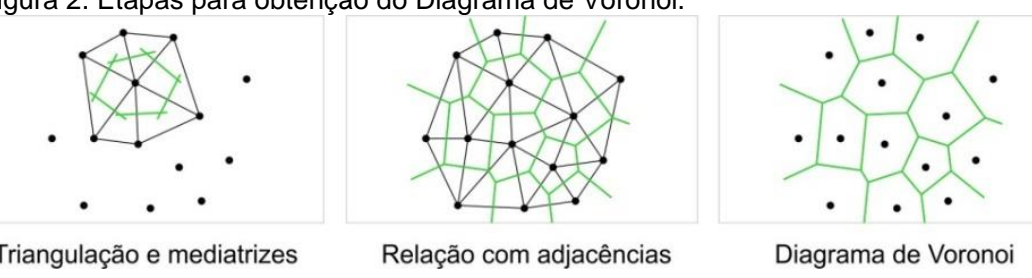

Fonte: Adaptado de EMIRIS; FISIKOPOULOS (2009).

Observe que no resultado acima, os polígonos externos se estendem infinitamente, e por isso são desenhados como figuras abertas. Os vértices dos polígonos estão ligados a três ou mais arestas e, portanto, são pontos de equidistância entre três ou mais locais. A geometria surgida pelo Diagrama de Voronoi constituise num fenômeno de organização que se aproxima dos mais diversos casos de arranjo celular. Essa simplicidade é recorrente em diferentes escalas, materiais e processos de ajustes naturais. $\mathrm{Na}$ arquitetura e no urbanismo as aplicações mais evidentes tratam de localizar distâncias entre pontos e trajetos, nos cálculos de proximidade, nos cálculos de regiões mais desocupadas, etc. (EL DALY, 2009).

O diagrama de Voronoi é tão ostensivamente explorado que diversos incrementos foram introduzidos ao longo dos anos. Testes com diversas posições dos pontos alteram o equilíbrio geométrico que surge dessa interação. Veja na Figura 3 algumas das principais variações criadas: o primeiro exemplo constitui o passo inicial no cálculo do Diagrama de Voronoi multiplicativamente ponderado, ou Diagrama de Apolônio, onde as linhas curvas surgem por conta dos diferentes pesos atribuídos aos pontos (graus de influência). O segundo exemplo trata do arredondamento interno dos polígonos, fazendo surgir um modelo próximo ao de uma esponja. Em seguida, a utilização de retas ou polígonos na definição das células e, por fim, a distribuição dos pontos estendidos ao infinito, como ocorre com um fractal. Todos os exemplos são desdobráveis para estruturas tridimensionais.

Figura 3. Testes computacionais com o Diagrama de Voronoi.

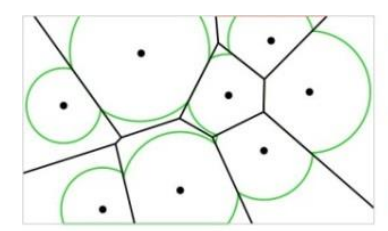

Pontos com diferentes pesos

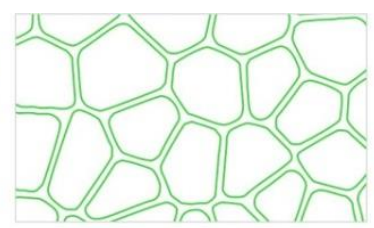

Arredondamento de arestas

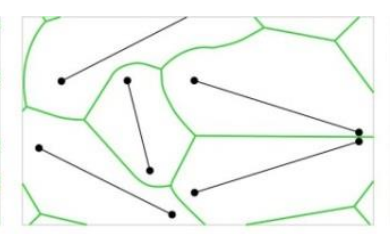

Retas na definição das células

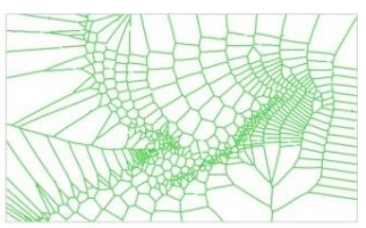

Voronoi fractal

Fonte: Adaptado de EMIRIS; FISIKOPOULOS (2009).

\section{Triangulação de Delaunay}

É um processo de organização e divisão espacial criado pelo russo Boris Nikolaevich Delaunay, em 1934. Para um dado conjunto de pontos, faz-se a união entre eles de modo a formar triângulos. Para que o arranjo possua qualidades de otimização espacial e de boas adequações nos seus vínculos, a Triangulação de 
Delaunay produz um conjunto de triângulos topologicamente organizados que atendem a seguinte propriedade: o círculo que é formado por três vértices do triângulo não pode conter nenhum outro ponto em seu interior (ver Figura 4). Esse critério faz com que as malhas tenham importantes propriedades geométricas, na medida em que a maioria dos triângulos tende para sua forma equilátera, melhorando o desempenho do grupo (TSAl, 1993).

Figura 4. Condições para a Triangulação de Delaunay.

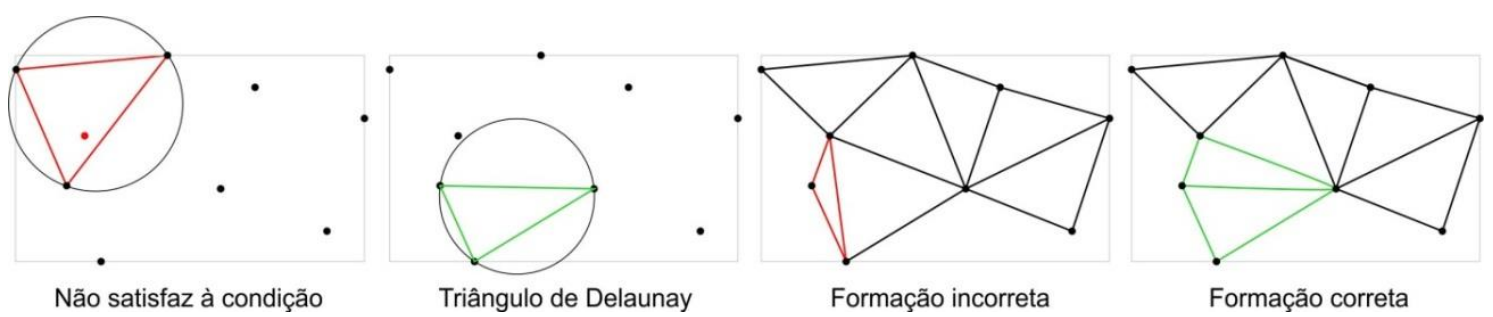

Fonte: Adaptado de EMIRIS; FISIKOPOULOS (2009).

Num dado conjunto quaisquer de pontos, a melhor opção de vínculos é a que corresponde ao Diagrama de Delaunay, o último quadro da sequência apresentada pela imagem acima. Esse princípio de Delaunay é muito importante porque os ângulos dos triângulos participam de um processo estável de organização. Há uma dinâmica lógica cujo objetivo é maximizar essas formas triangulares. Isso não apenas se justifica nos usos das aplicações arquitetônicas (estruturas com treliças metálicas, treliças espaciais, composição de malhas irregulares, etc.), como também na formação de quaisquer outros objetos tridimensionais descritos computacionalmente.

Para ilustrar essa teoria e poder observar alguns resultados na prática, seguem alguns exemplos de edifícios que se utilizaram dessas técnicas.

\section{WESTENDGATE}

O edifício WestendGate, também conhecido como Marriot Hotel possui 47 andares e foi, por algum tempo, a construção mais alta da Alemanha. Construído em 1976 pelos arquitetos Siegfried Hoyer e Richard Heil em Frankfurt, sua reforma foi iniciada em 2010. Os escritórios Just Burgeffarchitekten + a3lab dentre diversas alterações, propuseram uma nova cobertura de acesso e um novo design para a fachada. A ideia principal para a marquise de acesso é que ela gerasse uma extensão do espaço urbano adjacente. Assim, foi desenvolvida uma estrutura de modelo arbóreo para conduzir a uma nova identidade corporativa, reconhecida a longa distância pelas suas enormes proporções. São $1.000 \mathrm{~m} 2$ de superfície estendida a uma altura de 14 metros, servindo como marcação da entrada e abrigo para os funcionários dos escritórios e hóspedes do hotel.

O projeto da cobertura buscou integrar o edifício com a paisagem urbana, gerando um espaço intermediário de relação. O modelo da estrutura baseia-se num algoritmo que simula o crescimento das árvores, otimizado ainda pelo método de Análise de Elementos Finitos, de modo que pudesse ter adequações na estrutura de aço (ver Figura 4). "A técnica é subdividir os componentes estruturais em pequenas partes, ou elementos, e aplicar equações matemáticas para modelar o comportamento de cada pequeno elemento e a interação entre eles, modelando assim, a estrutura como um todo" (SILVER, 2013, p. 57). As equações são resolvidas simultaneamente a fim de se encontrar uma solução aproximada, prevendo como irá se comportar quando estiver sob carregamento.

Figura 5. Estrutura arbórea da cobertura de acesso ao WestendGate.

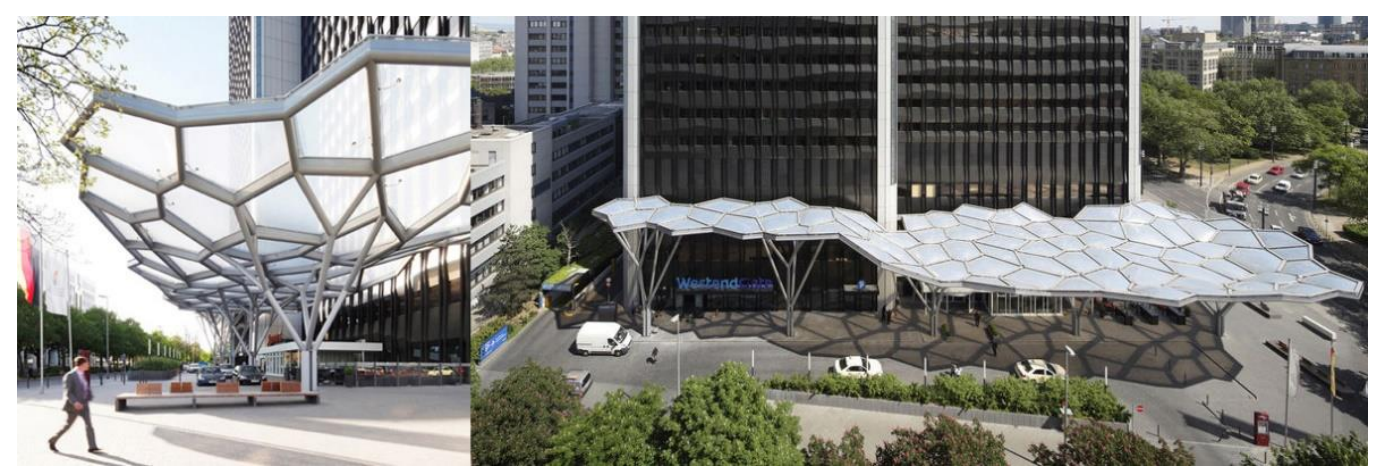

Fonte: JUST / BURGEFF ARCHITEKTEN (2016). 
A superfície gerada é irregular, com variações de alturas e declividades das Células de Voronoi, com as cargas conduzidas pelas várias ramificações e também bifurcações dos conjuntos de pilares. Os tubos de aço são de mesmo diâmetro, mas com espessuras de chapas diferentes, situação igualmente lógica da natureza, que aumenta o fuste para suportar o maior peso do conjunto. Desse modo, enquanto as Células de Voronoi integram esforços conjuntos de tração e flexão, transferem as cargas por estratégias geométricas nos pontos nodais de eixos múltiplos. "As formas estruturais 'vetor-ativa' fazem transferência de forças através de uma série de elementos rígidos interligados, que são pequenos em comparação ao comprimento do conjunto estrutural e, portanto, incapazes de desenvolver forças de flexão ou de cisalhamento significantes" (SILVER, 2013, p.60). Os pilares arbóreos foram soldados preliminarmente e, após a galvanização, foram aparafusados nas cabeças dos blocos de fundação, tornando a montagem mais rápida.

Cada porção da superfície da Célula de Voronoi foi adaptada para receber o plástico almofadado ETFE, termoplástico transparente de grande durabilidade, alta resistência química e mecânica, assim como também capaz de suportar grandes variações de temperatura. O ETFE é considerado o substituto do vidro, pois pesa 100 vezes menos, deixa passar a luz e pode ser usado com lâmina dupla. O plástico almofadado permite proteção contra o sol e a chuva e é translúcido, permitindo assim desejada transparência para a fachada do edifício (ARCHDAILY, 2011). Desse modo a superfície funciona como um grande guarda-chuva, por meio da sua extensão capta a água e também a canaliza para dentro dos pilares. Esse dossel marca a entrada conjugada do edifício e cria impactante identidade visual.

Uma grande vantagem no uso das Células de Voronoi é que podem gerar mudanças na extensão da forma pela inserção de novos pontos estrategicamente posicionados (ou também a retirada de outros anteriormente colocados), produzindo novas extensões controladas, nos melhores ajustes desejados (EMIRIS; FISIKOPOULOS, 2009). Uma mudança pontual atinge apenas os formatos das células próximas, resguardando as porções posteriores. Essa complexidade pode acontecer de modo gradual e também ainda a obedecer outras segundas funções, em casos onde a geometria inicial pode aninhar outra.

O uso das Células de Voronoi se justifica assim principalmente por conta das suas propriedades geométricas, da interação conjunta. Essa é uma propriedade que ocorre tanto nos modelos bidimensionais quanto tridimensionais. A irregularidade da disposição permite que as forças tenham interessantes características estruturais, no modo de se contrabalancearem. Essas propriedades geométricas tornam-se essenciais porque podem proporcionar uma vantagem na lógica tectônica dos trabalhos projetados com o auxílio do computador.

\section{UN MEMORIAL}

Com o design biomórfico e os processos biomiméticos cada vez mais explorados no mundo todo, o escritório de arquitetura ACME, com sede em Londres, também tem se apropriado desses conceitos. Como exemplo projetado pelo escritório, o Memorial das Nações Unidas recebeu o terceiro prêmio para a competição do Parque da Paz da ONU, em 2009. A proposta da ACME é um projeto especulativo composto por uma assembleia de 1.500 assentos, duas salas de conferências, um teatro e diversos espaços para exposição. A forma do edifício foi modelada como metáfora à ONU, onde muitas partes compõem um todo. Nesse caso, as diversas nações individuais dão forma ao edifício, agenciadas em Células de Voronoi tridimensionais (ver Figura 6). Segundo os autores, as células representam a "natureza coletiva da identidade da ONU" (ACME, apud CILENTO, 2009), agregadas para dispor a ordem final do edifício.

Figura 6. UN Memorial projetado pela ACME.

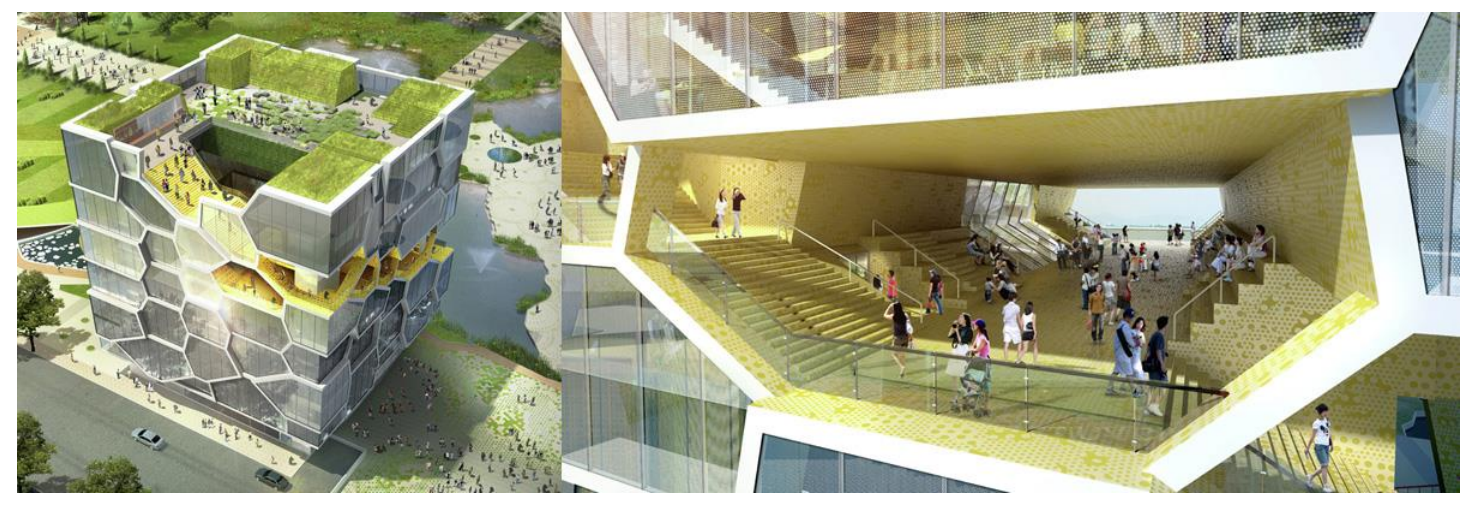

Fonte: (ARCH20, 2009).

Cada unidade foi projetada para ter uma função diferente: espaços para exposições, escritórios, restaurantes. A ACME explicou que o "[...] memorial deve representar a natureza das Nações Unidas, onde muitas nações 
individuais se unem para criar uma entidade, mas sem perder suas identidades individuais" (ACME in CILENTO, 2009). Também como estratégia de projeto, a parte superior do edifício é escavada, configurando um enorme vazio para permitir a iluminação natural. A luz penetra por todo seu interior e chega até o teatro principal, ocasionando grande efeito cênico.

A divisão espacial, baseada no Diagrama de Voronoi, traduz a relação de unidades em interfaces comuns na divisão do volume em células individuais. É uma estrutura de seção-ativa (ENGEL, 2013), a depender das características geométricas das seções de cada um dos elementos rígidos, vigas e pilares. "Os elementos de um sistema seção-ativo são projetados para resistir à flexão, cisalhamento e torção, assim como à tração e à compressão axiais" (SILVER, 2013, p. 62).

Cada ponto gera uma célula e, ao alterar as posições dos pontos visando estratégias funcionais do edifício, foi possível criar domínios singulares das porções, atribuindo pesos para que ocupassem maior ou menor tamanho conforme a necessidade de uso em cada ambiente. Nesse tipo de divisão espacial, diferentes configurações de pontos resultam em muitos tipos de células, capazes de se alterarem à medida que esses pontos são deslocados. Com o auxílio do computador, esses pontos podem ser animados, sendo possível observar os ajustes geométricos realizados gradualmente pela imposição da regra que forma a unidade.

Um princípio especial foi adicionado ao controle das células, onde cada ponto deve ser relativamente ortogonal ao seu ponto vizinho, solicitando a maior superfície no plano horizontal, e assim podendo gerar as lajes planas. Muitas porções inclinadas foram ajustadas para escadarias, arquibancadas, arenas de apresentação. Outras porções menos inclinadas, com vedações em ângulos irregulares, não representaram problemas porque a desigualdade foi tomada como expediente positivo. Desse modo, espaços práticos e dramáticos puderam coexistir no sistema (ver Figura 7).

Figura 7. Restrições aplicadas às células na formação dos ambientes.

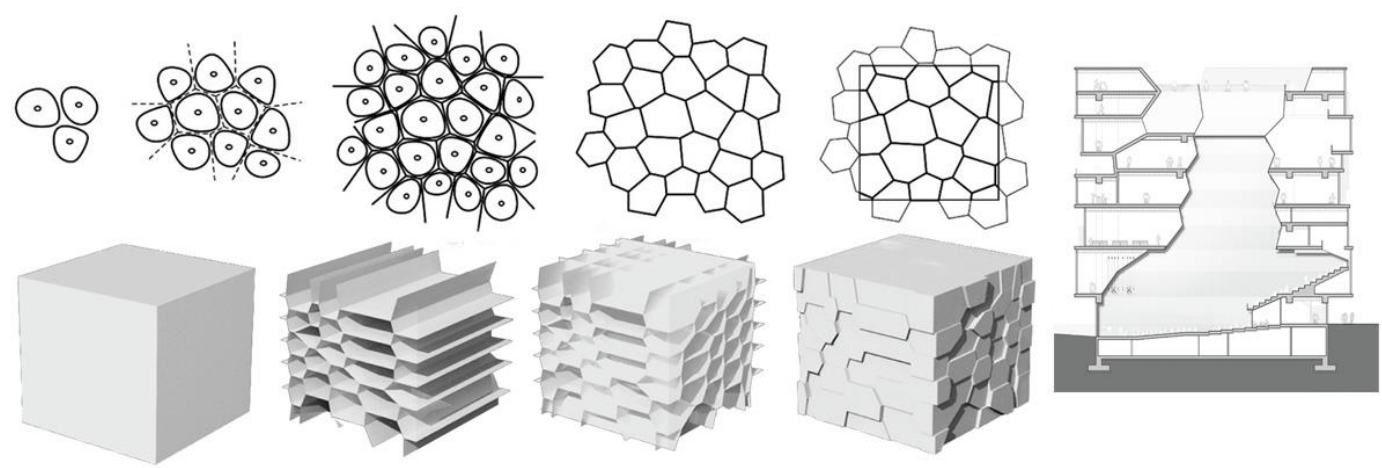

Fonte: ARCH20 (2009).

\section{ZKOTE TARASY}

O Złote Tarasy é um complexo comercial, de escritórios e de entretenimento no centro de Varsóvia, na Polônia. O conceito arquitetônico de Złote Tarasy desenvolvido pelo escritório The Jerde Partnership é baseado nos simuladores de tecido, originando a forma livre da cobertura. O edifício possui uma área total de $205.000 \mathrm{~m}^{2}$, incluindo 200 lojas, restaurantes, salas de cinema, diversas áreas de convivência. Inaugurado em 2007, o design da cobertura apresentou-se tão complexo que somente por meio da triangulação seria possível executá-lo (ver Figura 8).

Figura 8. ZłoteTarasy em Varsóvia. Fonte:

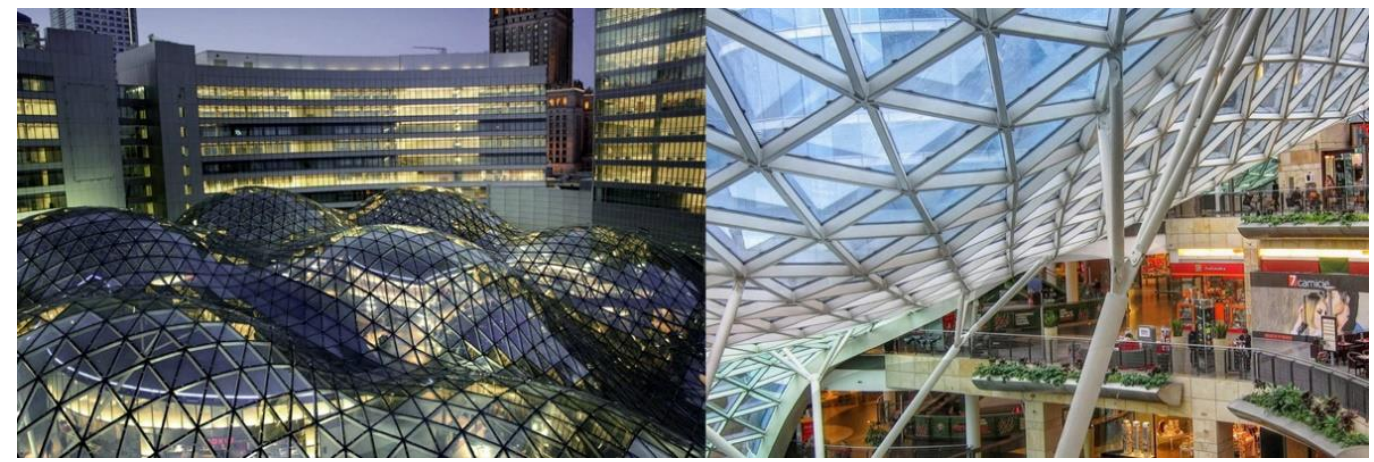

Fonte: <http://www.jerde.com/places/detail/zlote-tarasy> Acesso em 02 fev 2016. 
Diversas esferas foram estrategicamente produzidas para lugares específicos, onde eram requeridas maiores amplitudes espaciais. Posteriormente, para que a superfície irregular fosse amenizada, realizaram a simulação computacional de tecido em sobreposição a elas (JERDE, 2009) (ver Figura 9). O resultado é uma enorme superfície branda, com a típica fluidez de substâncias em estado líquido. Diante de uma forma tão complexa, a triangulação tornou-se a solução mais viável para a racionalização da forma livre. Para uma superfície muito irregular a utilização da Triangulação de Delaunay produziria triângulos com diversas alterações de tamanho, dificultando a execução das peças, tornando a montagem difícil e cara. A suavização da superfície permitiu a regularidade na formação dos triângulos e o consequente desembaraço da sua montagem.

Figura 9. Desenvolvimento da superfície da cobertura.

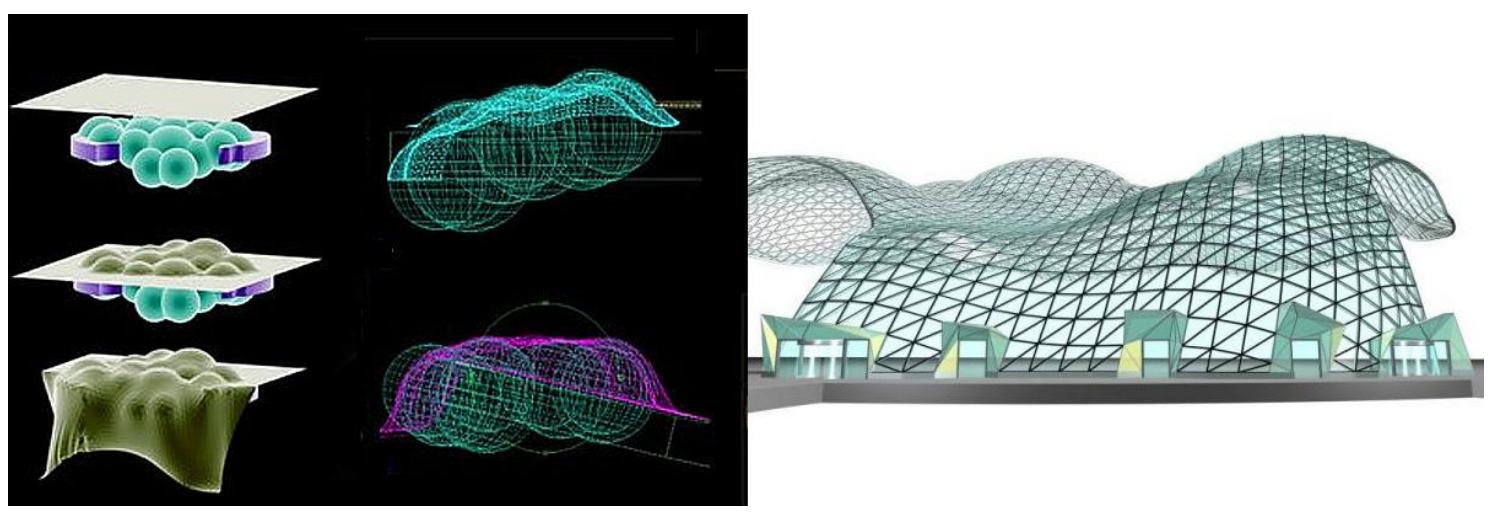

Fonte: VASS, 2006.

A triangulação pode ser considerada uma das medidas mais racionais para desenvolver superfícies curvas, formas livres. Mesmo sendo relativamente fácil representá-la no computador, a execução torna-se difícil, independentemente de qual material se adote (alumínio, ferro, latão, aço, etc.). Para que hajam métodos controlados, seguros e estáveis na execução de formas arquitetônicas (irregulares ou não), o uso de triângulos na racionalização de formas complexas tem sido adotado a séculos. O aspecto fundamental na triangulação das formas livres é que assim são fabricadas mais facilmente. Em unidades menores podem ser dispostas em arranjos mais simples. Mesmo uma malha de triângulos irregulares é mais fácil de fabricar, já que eles podem ser reduzidos a sistemas planos. Um conjunto de hastes formadoras de superfícies planas combinadas compõem formas curvas e, observadas a certa distância, a fragmentação de cada trecho no conjunto será considerada irrelevante.

Assim, uma das características mais importantes da Triangulação de Delaunay é que a precisão a ser trabalhada nas superfícies pode ser levada ao extremo, como ocorre em modelos computacionais onde se requer a máxima aproximação da curva de borda. Essa situação assemelha-se muito à estrutura do fractal, já que a triangulação pode atingir níveis mínimos de contorno, caso se queira. Por outro lado, o problema da Triangulação de Delaunay está justamente na aproximação dessa superfície, de modo que atenda a critérios estéticos (a malha deve ter aspecto agradável, triângulos com boa expressão visual), estruturais (condução adequada de trações, compressões, flexões, etc.), econômicos (quantidade de peças com baixo custo). Nesse sentido, cada caso precisa ser estudado nessas variáveis.

\section{DEFERÊNCIAS GERAIS DAS TÉCNICAS}

A triangulação de Delaunay é conhecida também por ser um grafo dual de Voronoi: ambos possuem uma etapa matemática e lógica comum. Isso se torna evidente quando os centros das circunferências (dadas pelos três vértices dos triângulos) são conectados, surgindo o outro diagrama (ver terceiro quadro da Figura 2 onde são vistos em sobreposição). No processo de triangulação a busca pela solução dada à malha é a sua organização com triângulos de melhor adaptação, de maior aproximação equilátera, dando estabilidade conjunta. Além disso, as respostas dadas pela triangulação podem ser mais bem ajustadas, ao se notar a baixa formação dos ângulos dos triângulos. Quando surgem ângulos muito obtusos ou muito agudos estes representam trechos de fragilidade estrutural, apontados visualmente pelo método (ver Figura 10).

A partir desses exemplos torna-se claro que as aplicações nos projetos de arquitetura são variadas e ocorrem em função de diferentes focos de interesse, onde o ponto pode ser considerado como uma entidade com outras designações, tratado de forma ponderada em relação a outros, como em hierarquias de prioridade (KOLAREVIC, 2003). Podem ainda compor superfícies de fachadas e outros elementos, além de estruturas tridimensionais para os mais diversos fins, criando sistemas altamente expressivos. Existem inúmeros 
exemplos de projetos com o Diagrama de Voronoi na arquitetura e os mais conhecidos são Alibaba Headquarters em Hangzhou, projeto de Hassell Studio; Water Cube, National Swimming Center, Beijing, China, projeto de PTW Architects e John Bilmon; Eden Project, em Cornualles, Inglaterra, de Nicholas Grimshaw; a Cúpula del Milenio, em Zaragoza, de Enric Ruiz-Geli; o Hospital General Dr. Manuel Gea González, no México, de Allison Dring e Daniel Schwaag; Airspace Tokyo, no Japão, de Thomas Faulders Architecture e Studio M, apenas para citar alguns.

Nos cálculos do Diagrama de Voronoi e da Triangulação de Delaunay, a posição dos pontos no espaço pode resultar retículas uniformes ou, de modo mais frequente, irregulares, em circunstâncias de adaptação ou também relativas a problemas específicos. A partir dessas configurações mais variadas possibilitam criar uma referência geométrica estável e coesa. Ambas podem ser entendidas como estratégias de formação espacial, respeitando inclusive pontos fixos a coexistirem no sistema. As divisões podem se adequar às complexidades tanto de contorno quanto dos requisitos de preexistência. A maximização das formas torna-se fundamental porque além de cobrir a maior área possível, a torna rigidamente estável.

Figura 10. Tabela das principais características.

\begin{tabular}{ll}
\hline Diagrama de Voronoi & - células ou polígonos convexos que compartilham faces e se ajustam \\
& perfeitamente; \\
& - podem ser ampliadas ad infinitum em qualquer direção, sem falhas ou lacunas, \\
& mantendo regularidade; \\
& - divisão do espaço capaz de estabelecer ritmo visual e uniformidade expressiva, \\
& assim como também de referências prefixadas; \\
& - os polígonos convexos possuem o mínimo de ligações e há um processo de ajuste \\
& simultâneo entre eles, ocupando o maior volume possível. \\
& - formação de triângulos com disposição máxima para sua forma equilátera; \\
& - aplicada principalmente a superfícies irregulares, racionalização de formas livres, \\
& formação de retículas; \\
Triangulação de Delaunay & - para estruturas tridimensionais torna-se sempre necessário incluir outros \\
& processos com cálculos complementares; \\
- o ritmo dos módulos triangulares é expressivo e adaptável a pontos preexistentes; & - novos pontos podem ser acrescentados ou removidos e afetam apenas as \\
& adjacências.
\end{tabular}

Fonte: Sintetização realizada pelo autor, 2017.

\section{CONSIDERAÇÕES FINAIS}

Por meio do computador torna-se possível uma reprodução simplificada das estruturas naturais, de grande interesse não apenas por arquitetos como também por engenheiros, apresentando aspectos técnicos de situações especiais. De modo mais investigativo que no passado, os arquitetos e engenheiros atuais são capazes de articular conceitos advindos de outras áreas na inspiração para resolução de problemas de projeto.

A noção de ordem num arranjo constitui fator essencial que rege a construção de uma forma inteligível já que uma forma é afinal o que aparece ao espectador como não sendo o resultado do acaso: a forma é consciência de previsibilidade no arranjo dos elementos. A forma, por mais complexa e irregular que seja, a ser tomada no empréstimo para alguma circunstância, é resultante de um continuum de fatores lógicos a serem detectados. Muitas geometrias naturais de estruturas intricadas constituem padrões organizados de comportamento (dentro de sistemas que aparentemente podem encontrar-se em desordem).

Desse modo, as tecnologias computacionais viabilizam dinâmicas de processos das arquiteturas digitais, pois o espaço gerado pelos computadores possibilita desenvolver inúmeras experiências singulares, explorando diversas estratégias de concepção de modelos arquitetônicos e estruturais. Esse espaço virtual permite especular propostas muito variadas, com grandes diferenças daquelas concebidas por meio de atividades e suportes tradicionais. A partir dessas tecnologias computacionais, as resultantes arquitetônicas apresentam novas formas e podem simular aspectos das limitações físicas determinadas pelos usos dos materiais (formas, dimensões, resistências, interações entre forças, etc.).

Uma das maneiras com que podem ser qualificadas as produções arquitetônicas na contemporaneidade relaciona-se à intensa energia criativa com a qual vem sendo desenvolvida, cujos resultados não são designados por processos projetuais simples. Fazer chegar nesse limite implica em procurar continuamente 
novas relações espaciais e recriar procedimentos já conhecidos, numa demanda que não cessa. A constituição de um espaço virtual obtido pelos recursos computacionais possibilitou a criação de inúmeros levantes formais, nas suas mais improváveis variantes, com técnicas de expressões e linguagens complexas, bastante diferentes daquelas concebidas até então.

\section{REFERÊNCIAS}

ARCH20. Un memorial / ACME, 2009. Disponível em: <http://www.arch2o.com/un-memorial-acme/>. Acesso em: 7 fev. 2017.

ARCHDAILY. WestendGate, Just Burgeffarchitekten + a3lab, 2011. Disponível em: <http://www.archdaily.com/?p=175519>. Acesso em: 7 fev. 2017.

CILENTO, Karen. UN Memorial / ACME, 2009. ArchDaily. Disponível em: <http://www.archdaily.com/37318/un-memorialacme>. Acesso em: 7 fev. 2017.

EL DALY, Hazem M. T. Revisitingalgorithms in architectural design. Towards new computational methods. Doctorate Thesis, Ain Shams University, Egypt, 2009. Disponível em: <http://www.cpas-egypt.com/pdf/Hazem_ElDaly/Ph.D/REVISITING\%20ALGORITHMS\%20IN\%20ARCHITECTURAL\% 20DESIGN.pdf>. Acesso em: 2 fev. 2016.

ENGEL, Heino. Sistemas estruturais. Trad. Esther Pereira da Silva. São Paulo: Gustavo Gili, 2013.

EMIRIS, Ioannis; FISIKOPOULOS, Vissarion. Voronoi diagram and Delaunay triangulation. Dept. of Informatics \& Telecommunications, University of Athens. 2009. Disponível em: <https://eclass.uoa.gr/modules/document/file.php/D42/ \%CE\%94\%CE\%B9\%CE\%B1\%CF\%86\%CE\%AC\%CE\%BD\%CE\%B5\%CE\%B9\%CE\%B5\%CF\%82/2a.delaunay.pdf>. Acesso em: 2 fev. 2016.

JERDE. Złote Tarasy. The Jerde Partnership, 2009. Disponível em: <http://www.jerde.com/places/detail/zlote-tarasy>. Acesso em: 7 fev.. 2017.

JUST / BURGEFF ARCHITEKTEN. Westend Gate, Frankfurt am Main, 2016. Disponível em: <http://just.burgeff.de/en/projects/ westendgate>. Acesso em: 7 fev. 2017.

KOLAREVIC, Branko. Architecture in digital age: design and manufacturing. Nova lorque: Spon Press, 2003.

KOTNIK, Toni. Algorithmic Extension of Architecture. Arch CAAD Thesis, Zurique, 2006. Disponível em: <http://wiki.arch.ethz.ch/ twiki/pub/MAS0506stu/NDSToniKotnik/ToniKotnik_ThesisMAS2006_Small.pdf>. Acesso: 8 fev. 2014.

SILVER, Pete et al. Sistemas estruturais. Trad. Janete Santana. São Paulo: Blucher, 2013.

TOLEDO, R. et al. A difusão de inovações tecnológicas na indústria da construção civil. In: Encontro Nacional de Tecnologia do Ambiente Construído, 8, 2000, Bahia. Anais... Bahia: ANTAC, 2000.

TSAI, Victor J. D. Fasttopologicalconstructionofdelaunaytriangulationsandvoronoidiagrams. Elsevier: Universityof Wisconsin-Madison, Madison, USA, 1993.

UN MEMORIAL. ACME Architects, 2010. e-architects. Disponível em: <https://www.e-architect.co.uk/korea/un-memorialchungju>. Acesso em: 7 fev. 2017.

VASS, Albert. Design in perspective. 2006. Disponível em: <http://www.studiovass.com/folio1/index-svi03.htm>. Acesso em: 2 fev. 2016.

NOTA DO EDITOR $\left(^{*}\right)$ O conteúdo do artigo e as imagens nele publicadas são de responsabilidade do(s) autor(es). 